\title{
Carrier-Distillation Method for Spectrographic Analysis and Its Application to the Analysis of Uranium-Base Materials ${ }^{12}$
}

\author{
By Bourdon F. Scribner and Harold R. Mullin
}

\begin{abstract}
A method of fractional distillation in the direct-current are was developed for the spectrographic determination of 33 volatile impurity elements at concentrations as low as a fraction of a part per million in uranium-base materials. The method involves (1) the conversion of the sample matrix to a form having low volatility, (2) the addition of a small amount of a selected volatile "carrier" material, and (3) partial distillation of the mixture in a direct-current are with an electrode assembly of improved design. In the analysis of uranium-base materials, the sample was converted to the oxide $\mathrm{U}_{3} \mathrm{O}_{8}$ and gallium oxide was added as a carrier ( 2 parts $\mathrm{Ga}_{2} \mathrm{O}_{3}, 98$ parts $\mathrm{U}_{3} \mathrm{O}_{8}$ ). The procedure was applied to the determination of $\mathrm{Ag}, \mathrm{Al}, \mathrm{As}, \mathrm{Au}, \mathrm{B}, \mathrm{Ba}, \mathrm{Be}, \mathrm{Bi}, \mathrm{Cd}, \mathrm{Co}, \mathrm{Cr}, \mathrm{Cs}, \mathrm{Cu}, \mathrm{Fe}, \mathrm{Ge}, \mathrm{Hg}, \mathrm{In}, \mathrm{K}, \mathrm{Li}, \mathrm{Mg}$, $\mathrm{Mn}, \mathrm{Mo}, \mathrm{Na}, \mathrm{Ni}, \mathrm{P}, \mathrm{Pb}, \mathrm{Rb}, \mathrm{Sb}, \mathrm{Si}, \mathrm{Sn}, \mathrm{Tl}, \mathrm{V}$, and $\mathrm{Zn}$. Repeated results for $\mathrm{B}, \mathrm{Cd}, \mathrm{Si}, \mathrm{Fe}, \mathrm{Mg}$, and $\mathrm{Mn}$, determined photometrically, agreed within \pm 10 percent. The high sensitivity and general applicability of the method are results of the characteristic that the refractory sample matrix is not volatilized appreciably, during the period that the minute quantities of impurity vapors are swept into the are by the carrier.
\end{abstract}

\section{Introduction}

The factors entering into the utilization of uranium as a source of atomic energy have been discussed by Smyth [1].* One of the limitations in attaining a nuclear chain reaction lies in nonfission capture of neutrons by impurities. The impurities differ in this absorptive power, but

\footnotetext{
*Figures in brackets indicate the literature references at the end of this paper.

1 This investigation was sponsored by the Office of Scientific Research and Development and by the Manhattan Project. The information covered in this document will appear in Division VIII of the Manhattan Project Technical Series, as part of a contribution of the National Bureau of Standards.

2 Presented at the meeting of the Optical Society of America on March 8, 1946.
}

I. Introduction

Contents

II. Discussion 379

1. The carrier and its function 381
II. Discussion-Continued Page

2. Arc excitation _... 381

3. Standard samples. _. _ _ _ _ _ _ 384

4. Results _. _. 384

III. Experimental procedures____ _ _ _ _ 385

1. Apparatus__._. 385

2. Analysis of uranium-base materials_... 386

(a) Preparation of the sample _... 386

(b) General procedure: determination of 26 elements. . . . . . 387

(c) Improved determination of $\mathrm{Fe}$, $\mathrm{Mg}$, and $\mathrm{Mn}$

(d) Determination of $\mathrm{Cd}$ and $\mathrm{Hg}_{-}-388$

(e) Determination of $\mathrm{Ba}, \mathrm{Li}$, and Na_ 388

(f) Determination of $\mathrm{Cs}, \mathrm{K}$, and $\mathrm{Rb}$ - 388

IV. Summary _._. 389

V. References_... 389 
certain common elements such as boron, lithium and cadmium are particularly effective. It had been shown by calculations that many impurities should not exceed a few parts per million and, in the case of the highly absorbing elements, freedom even from a few tenths parts per million was desirable. Impurities also have a deleterious but less-pronounced effect on the metallurgical properties of uranium metal. The production of uranium, to be used as a source of atomic energy, consequently involves a most searching analysis into the composition of the intermediate and final products. Methods were required for the determination of 60 or more chemical elements in a variety of uranium-base materials with speed, high-sensitivity, and sufficient accuracy as important considerations.

Early in 1941 this laboratory began an investigation of the applicability of spectrographic methods to this analytical problem. The principal obstacle encountered was the interference of the uranium spectrum with the spectral lines of the elements to be determined. Uranium is characterized by complex spectra derived from a multiplicity of electron configurations in both the neutral and ionized atoms. The spectra of different stages of ionization are difficult to isolate because of the low ionization potential of uranium, which is approximately 4 volts [2]. The rich linespectrum is further confused by a heavy background contributed by unresolved weak lines and by the continuous radiation of solid particles, a characteristic that is common to elements forming refractory oxides. Because of these properties little simplification could be realized by a choice between the usual excitation methods; furthermore, recourse to very high spectral dispersion appeared impracticable. It was apparent that sensitive spectrographic methods of general utility could be developed only by suppressing or otherwise avoiding the spectra of uranium atoms.

As a means of eliminating interference by the spectrum of uranium, fractional distillation in the d-c arc appeared promising. It is a wellknown fact that the constituents of a sample undergoing excitation for spectral study may distill at different rates, depending on their volatilities. This is particularly true in excitation by the $d$-c arc when the sample is contained in a cupped graphite electrode which acts much like a small furnace. In 1918 Mott [3] applied arc distillation phenomena in studying the volatilities of refractory materials, and in 1920 he suggested [4] the use of arc images to observe the volatilization of various constituents as a means of chemical analysis. Fractional distillation was later applied in spectrographic analysis by Rubies [5, 6], by Preuss [7] and others.

The application of simple fractional distillation was found unsatisfactory in view of the requirements for complete suppression of the uranium spectrum and for accurate control of excitation to permit quantitative determination of impurities. Variations in the chemical form of the uraniumbase sample, in its physical properties, and in total impurity content markedly affected the results. The problem lay in developing a means of distillation and excitation whereby trace impurities could be removed from the uranium matrix and their spectra recorded under conditions suitable for quantitative determination.

An investigation of the problem led to the development of a modified method of fractional distillation involving (a) conversion of the sample matrix to a form having low volatility, (b) addition of a small amount of a selected volatile "carrier" material, and (c) partial distillation of the mixture in a d-c arc under carefully controlled conditions. The method was first applied in 1942 to the determination of boron in uranium-base materials. It was subsequently extended, by the choice of suitable wavelengths and by the preparation of standards, to cover the determination of 33 volatile impurities. The limit of detection for the majority of the elements is a few parts per million, although, for important cases, the sensitivity was extended to less than $0.1 \mathrm{ppm}$. The degree to which uranium interference is avoided by this method, with resulting high sensitivity of detection of impurities, is exhibited in figure 1 . Exposures $A$ (direct burning) and $B$ (carrierdistillation method) were made with a sample containing $500 \mathrm{ppm}$ of $\mathrm{Al}$ and $\mathrm{Fe}$, and $50 \mathrm{ppm}$ of $\mathrm{Cu}$. Exposure $C$ (carrier-distillation method) represents a sample containing $50 \mathrm{ppm}$ of $\mathrm{Al}$ and $\mathrm{Fe}$, and $5 \mathrm{ppm}$ of $\mathrm{Cu}$. The method is generally applicable, with minor modifications and the proper standard samples, to the analysis of other refractory materials. The conditions under which the method is applied have a considerable bearing on its success, and these will be examined in detail. 
A

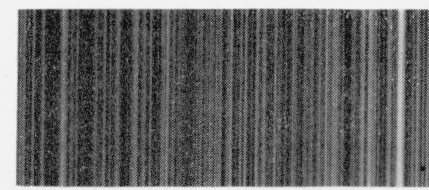

B

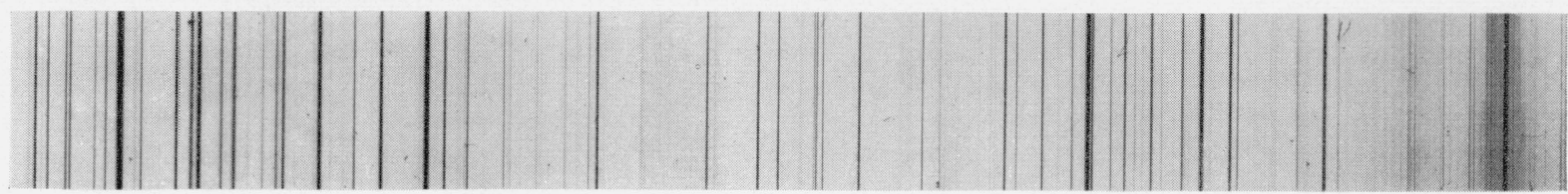

C

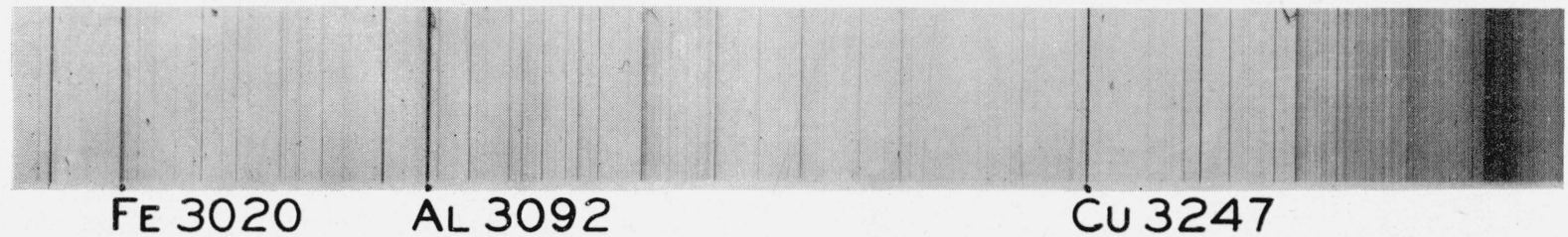

Figure 1.-Arc spectrograms in the region 3000 to $3350 \mathrm{~A}$.

4. Spectrum of $1 \mathrm{mg}$ of $\mathrm{U}_{3} \mathrm{O}_{8}$ by direct arcing; $B$, spectrum obtained from $100 \mathrm{mg}$ of $\mathrm{U}_{3} \mathrm{O}_{8}$ by the carrier-distillation method; $C$, same as $B$, except that the uranium sample is of higher purity. 


\section{Discussion}

\section{The Carrier and Its Function}

In studies of simple fractional distillation in the arc, a variety of uranium compounds of different degrees of purity were examined. Observing that the sensitivity of detection of a trace impurity was enhanced in the presence of other impurities, we investigated the effect of various additions to the uranium sample. In general, a marked increase in the sensitivity of volatile impurities was observed. Added materials of intermediate volatility were most effective, and conditions could be so adjusted that the volatile impurities would distill with the carrier, but only a trace of the uranium would be carried into the arc. The principal function of the added material, or "carrier", is to sweep out slowly the minute quantities of impurities volatilized by the heat of the electrode, thereby effecting a sharp separation from the more refractory matrix. At the same time, the carrier supports and stabilizes the arc.

The choice of a carrier involves certain limitations, but it may be expected that several materials will provide satisfactory results. However, salts such as ammonium chloride and sulfate were too volatile and, even in small amounts, introduced uranium into the arc. Alkali salts tended to suppress boron lines, possibly because of the depressing effect of the low ionization potential of the alkali metal in the arc. In general, the carrier should have an intermediate volatility and an intermediate ionization potential among the group of elements to be determined, be free of those elements, be stable, inert, nonhygroscopic and easily incorporated in the samples by grinding. In the analysis of uranium-base materials, where determinations of many elements were desired, the choice of a carrier narrowed down to an element of minimum importance, one that is not a common or critical impurity in the samples. Pure gallium oxide, one of the first materials tested as a carrier, satisfied the requirements and has been employed extensively for this purpose within the project. As gallium was readily determined in a chemical concentrate obtained for a supplementary spectrographic procedure, it was not necessary to consider its determination by the carrier-distillation method. Harrison and Kent [8] have recommended silver chloride as a possible substitute for gallium oxide.

Gallium oxide of the requisite purity was prepared by a procedure suggested by Hoffman and involving an ether separation which he has described [9]. Gallium metal is partially dissolved in hydrochloric acid, leaving a residue of 5 to 10 percent of the metal. The elements less active than gallium tend to concentrate in the residue, and in most instances this procedure suffices for purification. If necessary, an ether extraction may be made for further purification, and then the chloride is converted to oxalate, which finally is ignited to oxide at $1,200^{\circ} \mathrm{C}$.

The selection of the concentration at which the carrier is added to the sample is based upon the amount required to sweep out the impurities and to maintain a steady arc for a sufficient length of time for reasonable exposure of the photographic plate. The upper limit on the amount added is determined by the tendency of excessive amounts to carry particles of the uranium sample mechanically into the arc stream. The choice of a ratio of 2 parts of gallium oxide $\left(\mathrm{Ga}_{2} \mathrm{O}_{3}\right)$ to 98 parts of uranium oxide $\left(\mathrm{U}_{3} \mathrm{O}_{8}\right)$ has proved satisfactory. The dense form of gallium oxide, obtained by ignition at $1,200^{\circ} \mathrm{C}$, is preferred for ease in weighing and transferring. The carrier is incorporated in the uranium oxide by hand-grinding in a small mortar.

\section{Arc Excitation}

The form and dimensions of the arc electrode assembly have important effects on the rate and degree of heating of the charge. The electrode combination employed, figure 2 , is similar to that described by Scribner and Corliss [10], but it provides a deep cup in the anode in which the sample charge is heated. A further modification is the tapered fit between the cap and pedestal, providing accurate alinement of the electrode. The two-piece anode minimizes heat conduction from the anode cap, resulting in a high temperature and only moderate gradient from top to bottom of the cap. The charge thus is exposed to relatively uniform heating from the electrode wall, while direct contact with the arc stream is avoided. Prior to excitation, a charge of $100 \mathrm{mg}$ of the sample mixture (98 parts of $\mathrm{U}_{3} \mathrm{O}_{8}$ and 2 parts of $\mathrm{Ga}_{2} \mathrm{O}_{3}$ ) is transferred to the electrode, which is 
mounted in an electrode block. The electrode is tapped to distribute the charge evenly, and a vent hole is made vertically through the center of the charge. The vent serves to release gases that otherwise may cause ejection of the charge into the arc stream when the arc is struck.

The arc excitation of the samples is characterized by a cycle of burning that is quite reproducible for the purer grades. The electrodes are mounted as shown in figure 2 , with a separation of $4 \mathrm{~mm}$, and a 10-ampere are is struck. The arc burns somewhat erratically for about 10 seconds, being supported mainly by volatilization of the electrode material. At the end of this period the arc changes in color from indigo to blue and runs quietly and steadily for approximately 25 seconds,
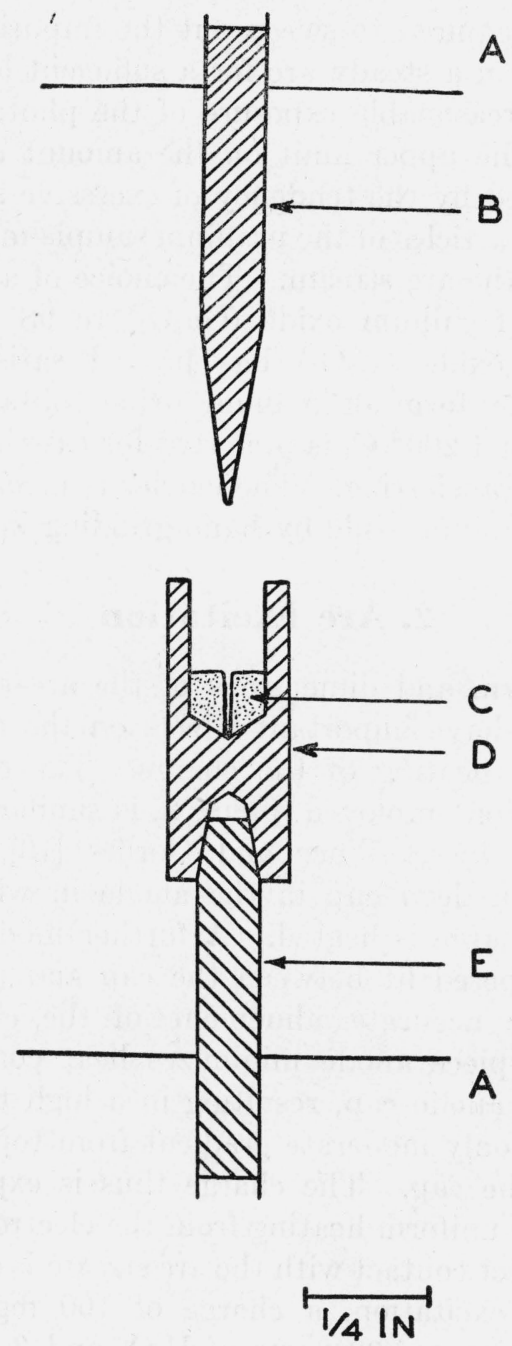

Figure 2.-Electrode assembly.

$A$, Holder; $B$, cathode; $C$, sample charge; $D$, anode; $E$, pedestal. changing at this point to the unsteady condition of the initial period. Studies by the moving plate technic have shown that the steady period results from distillation of the carrier and the greater part of the volatile impurities into the arc stream. However, certain highly volatile impurities, such as cadmium and mercury, begin to volatilize ahead of the steady period, and elements such as aluminum and magnesium, present as refractory exides, persist in the arc at the end of the steady period. During the volatilization of the gallium only a trace of the uranium is removed, and the spent charge may be set aside for recovery of the uranium.

Spectrographic analysis of the burned charges, made by repeating the procedure with a new portion of the carrier, has shown that the end of the steady period does not represent complete volatilization of even the more volatile elements. This is a necessary result of the restriction that the temperature must be kept below the limit at which the charge fuses and uranium is evolved. Observation of the burning electrode with an optical pyrometer showed that the outer surface reached a temperature of $2,800^{\circ} \mathrm{C}$ near the top of the electrode and $2,300^{\circ} \mathrm{C}$ near the bottom. The charge, heated by radiation from the interior wall of the electrode, sinters to a fragile cake but does not melt, which indicates that the temperature is slightly below the melting point of $\mathrm{U}_{3} \mathrm{O}_{8}$. The working temperature, estimated to be in the neighborhood of $2,000^{\circ} \mathrm{C}$, is below the boiling point or decomposition temperature of many of the impurity oxides; volatilization probably depends on their vapor pressures at the charge temperature. For most of the elements (gold is an exception), the volatility can be considered proportional to the boiling point of the oxide. ${ }^{3}$ The behavior of the impurities suggests a division into three groups in which the oxides have boiling points (a) below $1,500^{\circ} \mathrm{C}$, (b) around $2,000^{\circ} \mathrm{C}$, and (c) in the neighborhood of $3,000^{\circ} \mathrm{C}$. Impurities in the first group volatilize rapidly and nearly completely; those in the second group volatilize more slowly, resembling gallium oxide in behavior; those in the third group volatilize less completely, and the degree of volatilization is more severely affected by variations in the heating conditions.

\footnotetext{
8 The two papers by Mott $[3,4]$ contain much useful information on relative boiling points of elements and their compounds.
} 
The behavior of the first two groups of impurities permits satisfactory spectrographic determination by visual and photometric interpolation against standard samples handled in the same manner. For example, boron is determined by preparing an analytical curve, figure 3 , in which $\log$ intensity of the boron line is plotted against log

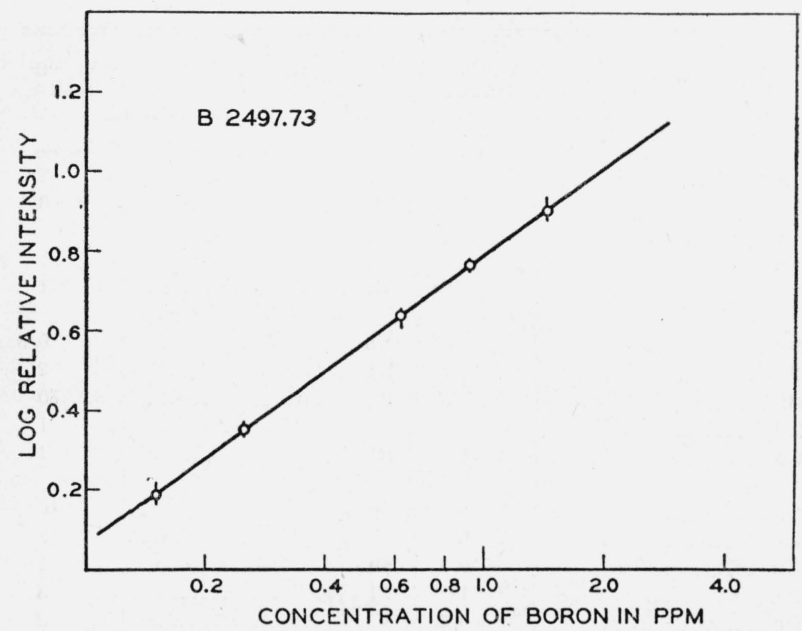

Figure 3.-Analytical curve for the determination of boron.

concentration of boron for a series of standard samples, each point representing four observations. Subsequent boron determinations are made by similar measurements on unknown samples and a reference standard on the plate, the log $I$ values are corrected to bring the reference standard into agreement with the curve, and the boron determinations are read from the curve.

For accurate determination of elements of the third, or low-volatility, group, the addition of an internal-control element was found necessary. In this case the intensity of the impurity line was measured relative to that of an added element which behaves similarly in volatilization. The determinations of iron, magnesium, and manganese, falling in this group, were made by photometric measurement relative to chromium added in the gallium oxide carrier $\left(\mathrm{Ga}_{2} \mathrm{O}_{3}\right.$ containing 1 percent of $\mathrm{Cr}$ as $\mathrm{Cr}_{2} \mathrm{O}_{3}$ ). An analytical curve for the determination of iron is shown in figure 4 .

Consideration of volatility is also important in adjusting exposure times in the analytical procedures. For second- and third-group elements, a portion of the initial burning period can be omitted from the exposure without appreciable error; this is useful in some cases in reducing spectral back- ground. For the first-group elements, which begin to volatilize almost immediately, the exposure is begun the moment the arc is struck, but the total exposure may be cut short if necessary, as in the case of determination of cadmium, to reduce background.

This discussion of excitation characteristics has assumed application to the purer grades of uranium-base materials. If the total content of volatile impurities in a sample rises toward 1 percent, the steady burning period will be longer. In these cases the results may be affected by the high concentration of volatile materials. Dilution of the impure sample by pure oxide $\left(\mathrm{U}_{3} \mathrm{O}_{8}\right)$ serves to obviate these effects, and the diluted sample may be analyzed according to the basic procedure for pure oxide, the results being corrected by the dilution factor. The conversion of uranium salts to uranium oxide prior to application of the method should be complete to avoid any volatilization of uranium; erratic behavior in arc distillation in several cases has been traced to incomplete conversion.

The ignition of a uranium-base material will result in loss of mercury. Furthermore, the con-

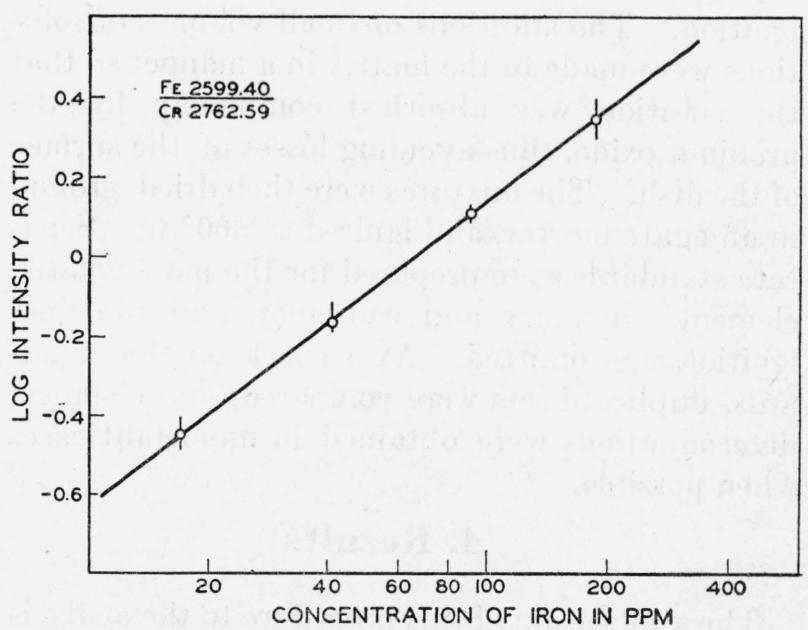

Figure 4.-Analytical curve for the determination of iron.

version of salts such as the fluoride $\left(\mathrm{UF}_{4}\right)$ may result in loss of boron and other elements having volatile fluorides. In these cases a separate examination of the original sample may be made for the elements in question, employing a modified carrier distillation procedure. Further details concerning special problems of this type are given in the experimental procedures. 


\section{Standard Samples}

The ultimate success of the method depends not only on excitation controls but on the availability of standard samples having concentrations and excitation behavior matching those of the samples to be analyzed. To obtain comparable behavior in volatilization, the samples and standards should be matched as closely as possible in density, and in the chemical forms of the matrix and of the impurities; volatile anions should be avoided. One of the difficult problems encountered was that of obtaining sufficiently pure material for a standard matrix. The materials found purest by spectrographic test usually contained traces of $\mathrm{B}, \mathrm{Cu}$, $\mathrm{Ag}, \mathrm{Mg}, \mathrm{Si}$, and $\mathrm{Fe}$, but in varying amounts. The difficulty in obtaining one lot of material free of all elements, and also the large number of impurities to be added, made it necessary to prepare several sets of standards. Series of standards were prepared, in general, by adding measured quantities of solutions of the impurity elements to weighed quantities (10 to $50 \mathrm{~g}$ ) of ignited uranium oxide $\left(\mathrm{U}_{3} \mathrm{O}_{8}\right)$ in platinum dishes. The solutions were prepared, as far as possible, with salts such as the nitrate which would convert to oxide on ignition. The additions of small volumes of solutions were made to the matrix in a manner so that the solution was absorbed completely by the uranium oxide, thus avoiding losses on the surface of the dish. The mixtures were then dried, ground in an agate mortar, and ignited at $800^{\circ} \mathrm{C}$. Separate standards were prepared for the more volatile elements, mercury and cadmium, and the final ignition was omitted. As a check on the standards, duplicate sets were compared, and chemical determinations were obtained in important cases when possible.

\section{Results}

The application of this procedure to the analysis of uranium-base materials permits the determination of 33 impurities, with the limits of detection given in table 1 . The limits are those observed in routine practice and do not necessarily represent the ultimate limit that may be obtained under the most favorable conditions. For example, conditions were adjusted for high sensitivity in the determination of cadmium and boron, but for an element, such as zinc, of lesser importance as a neutron absorber, special treatments that would add time-consuming complications were avoided. The sensitivities that were attained met the requirements for the determination of this group of elements in the inspection and control of the purity of uranium-base materials.

TABLE 1.-Lower limit of routine spectrographic determination of impurities in uranium oxide

\begin{tabular}{|c|c|c|c|}
\hline Element & $\begin{array}{l}\text { Concen- } \\
\text { tration }\end{array}$ & Element & $\begin{array}{l}\text { Concen- } \\
\text { tration }\end{array}$ \\
\hline Ag & $\begin{array}{l}p p m \\
0.05\end{array}$ & $\mathrm{~K}$ & $\underset{2}{p p m}$ \\
\hline $\mathrm{Al}$ & 5 & $\mathrm{Li}$ & 0.1 \\
\hline As & 5 & Mg ........ & .5 \\
\hline $\mathrm{Au}_{\mathrm{u}}$ & 0.3 & Mn & 1 \\
\hline B & .08 & Mo & 1 \\
\hline $\mathrm{Ba}$ & 10 & $\mathrm{Na}$ & 0.5 \\
\hline $\mathrm{Be}$ & 0.1 & $\mathrm{Ni} \ldots \ldots$. & 2 \\
\hline $\mathrm{Bi}$ & .5 & $P$ & 50 \\
\hline Cd & .07 & $\mathrm{~Pb}$ & 1 \\
\hline Co & 1 & $R b_{\ldots}$ & 1 \\
\hline 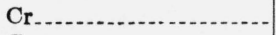 & 3 & Sb... & 10 \\
\hline Cs_............. & 8 & Si & 3 \\
\hline $\mathrm{Cu}$ & 0.3 & Sn & 1 \\
\hline $\mathrm{Fe}$ & 1 & Tl & 3 \\
\hline Ge & 0.2 & V $\ldots$ & 5 \\
\hline Hg & 10 & $\mathrm{Zn}$ & 20 \\
\hline In.... & 0.5 & - & . \\
\hline
\end{tabular}

The accuracy of the determinations by the method depends upon matching the excitation behavior of the samples and properly prepared standards, and upon the precision of the spectrographic measurements. Increased precision is provided by photometric measurement, but this advantage is offset by the additional time and labor required, which would be excessive if applied to all determinations. A compromise was adopted whereby the more important determinations were made by photometric measurement, and the remainder were estimated, usually within a factor of two, by visual comparison of the spectrograms of samples and standards. The reproducibility of determinations made for $\mathrm{B}, \mathrm{Cd}, \mathrm{Si}, \mathrm{Fe}, \mathrm{Mg}$, and Mn by photometric measurement was found to be within \pm 10 percent except for values at the extreme limits of the measurable range. For example, on a sample of uranium oxide containing $1.20 \mathrm{ppm}$ of boron, a series of 18 runs on 6 plates showed an average deviation of \pm 7.9 percent and an extreme deviation of 13 percent. Examples of repeated determinations of $\mathrm{Fe}, \mathrm{Mg}$, and $\mathrm{Mn}$ in uranium-base samples are given in table 2 . 
TABLE 2.-Repeated spectrographic determinations, of impurities in uranium-base samples

\begin{tabular}{|c|c|c|c|c|c|c|c|}
\hline \multirow{2}{*}{$\underset{\substack{\text { Sample } \\
\text { No. }}}{ }$} & \multirow{2}{*}{ Element } & \multicolumn{5}{|c|}{ Observation } & \multirow{2}{*}{ Mean } \\
\hline & & 1 & 2 & 3 & 4 & 5 & \\
\hline \multirow{4}{*}{150} & & & & $p p m$ & & & \\
\hline & \{ron & 28 & 32 & 30 & 28 & 27 & 29 \\
\hline & Manganese... & 7 & 7 & 8 & 9 & 7 & 8 \\
\hline & (Iron & 30 & 33 & 30 & 28 & 30 & 30 \\
\hline \multirow[t]{2}{*}{152} & Magnesium & 12 & 13 & 10 & 14 & 15 & 13 \\
\hline & |Manganese & 7 & 8 & 9 & 9 & 9 & 8 \\
\hline \multirow{2}{*}{157} & \{ron & 108 & 110 & 104 & 111 & 106 & 108 \\
\hline & Manganese & 14 & 13 & 12 & 12 & 14 & 13 \\
\hline \multirow{2}{*}{158} & $\{$ Iron $\ldots . . . . . . .$. & 89 & 76 & 77 & 87 & 88 & 83 \\
\hline & Manganese & 8 & 8 & 9 & 9 & 9 & 9 \\
\hline \multirow{2}{*}{162} & \{ron & 76 & 79 & 69 & 68 & & 73 \\
\hline & |Manganese_... & 11 & 9 & 11 & 11 & & 10 \\
\hline \multirow{3}{*}{165} & [Iron & 33 & 37 & 34 & 27 & & 33 \\
\hline & $\{$ Magnesium _......... & 35 & 33 & 30 & 36 & $\ldots \ldots$ & 33 \\
\hline & |Manganese............... & 10 & 8 & 8 & 9 & $\ldots$ & 9 \\
\hline
\end{tabular}

In view of the fact that the chemical determination of iron was considered quite reliable, it is of interest to compare routine results by the two methods on a typical set of uranium-base samples, as shown in table 3 . The chemical determinations were made in the Bureau's Chemistry Division.

The carrier-distillation method was applied to the quantitative determination of 33 elements in various uranium-base materials of interest to the
Manhattan Project. The materials included uranium metal, various oxides $\left(\mathrm{UO}_{2}, \mathrm{UO}_{3}, \mathrm{UO}_{4}\right.$, and $\left.\mathrm{U}_{3} \mathrm{O}_{8}\right)$, and salts $\left(\mathrm{UF}_{4}, \mathrm{UCl}_{4}, \mathrm{UF}_{6}\right.$, uranyl acetate and nitrate, and sodium uranate). In isolated cases when the method was extended to impure grades of samples or to a salt, such as sodium uranate, differing markedly from the available standards, the accuracy was adversely affected. In these cases qualitative results were reported as estimated ranges of concentration to a factor of 10. The great majority of analyses involved samples of high-grade uranium-base materials.

TABLE 3.-Determinations of iron in uranium-base samples by routine spectrographic and chemical methods

\begin{tabular}{|c|c|c||c|c|c|}
\hline $\begin{array}{c}\text { Sample } \\
\text { No. }\end{array}$ & $\begin{array}{c}\text { Spectro- } \\
\text { graphic }\end{array}$ & $\begin{array}{c}\text { Chemi- } \\
\text { cal }\end{array}$ & $\begin{array}{c}\text { Sample } \\
\text { No. }\end{array}$ & $\begin{array}{c}\text { Spectro- } \\
\text { graphic }\end{array}$ & $\begin{array}{c}\text { Chemi- } \\
\text { cal }\end{array}$ \\
\cline { 1 - 2 } & $-p p m$ & $p p m$ & & $p p m$ & $p p m$ \\
151 & 28 & 41 & 161 & 38 & 35 \\
152 & 32 & 35 & 162 & 77 & 74 \\
153 & 33 & 32 & 163 & 41 & 41 \\
154 & 149 & 154 & 164 & 83 & 79 \\
155 & 31 & 32 & 165 & 34 & 36 \\
& & & & & \\
156 & 26 & 32 & 166 & 19 & 24 \\
157 & 110 & 139 & 167 & 34 & 34 \\
158 & 83 & 70 & 168 & 26 & 31 \\
159 & 35 & 35 & 169 & 41 & 34 \\
160 & 33 & 31 & 170 & 38 & 42 \\
& & & & & \\
\hline
\end{tabular}

\section{Experimental Procedures}

\section{Apparatus}

The relative simplicity of the spectrum obtained by the carrier-distillation method permits the use of spectographs of moderate dispersion, although for high sensitivity the reduction of spectral background with increased dispersion is an advantage. A commercial grating spectrograph, Eagle mounting, having a dispersion of $5.6 \mathrm{~A}$ per $\mathrm{mm}$ in the first order, is employed for the procedures to be described. A step sector (step ratio $2 \times$, steps $2 \mathrm{~mm}$ high) and quartz lens $\left(f_{D}=44\right.$ $\mathrm{cm}$ ) are mounted at the secondary focus of the grating in the customary manner to focus an image of the arc source on the grating. By this means the sector intercepts a uniform beam of light and the spectral-line images appear as a pattern of exposures with the ratios of the exposures determined by the corresponding ratios of the opening in the step sector. The spectral line images then may be measured at optimum blackening values, and the line patterns may be employed for calibration of the plate. The usual facilities of a well-equipped spectrographic laboratory, including a direct-reading microphotometer, are sufficient for the work, although some additional minor equipment for preparation of samples and standards is required.

The minor equipment includes polished agate or mullite mortars, small balances designed for rapid weighing, drilled blocks for storing electrodes, and special tools for preparing electrodes. Torsion balances of the Milligram Balance type, with ranges of 0 to $50 \mathrm{mg}$ and 0 to $250 \mathrm{mg}$, have been employed. The balances were fitted with dish-shaped polished aluminum pans, in which a funnel-like hole was made to permit rapid transfer of powdered charges to the electrode. Tapping the side of the pan is sufficient to cause the powder to slide smoothly and completely through the hole 
into an electrode. The use of metal pans avoids the difficulty encountered with static electric charges when glass weighing dishes are employed. The anode caps for the electrodes, figure 5, are prepared from high-purity graphite rods on a cutter similar to that made by the ARL-Dietert Co., but provided with a drilling tool at each end of the motor shaft, one tool for drilling the sample cup and the other for drilling the tapered mounting cup. The dimensions of the drills and other tools are shown in figure 6 . The cathodes are sharpened to a point in a pencil sharpener fitted with a stainless-steel guide sleeve. The anode pedestal is readily prepared by placing the tip of a cathode electrode piece through the hole in the pedestal-forming tool (fig. 6) and then removing the protruding tip. The anode cap, $A$, is employed throughout the carrier-distillation procedure. Anode cap, $B$, is employed in a procedure involving complete burning of the sample, which, in the case of uranium oxide samples, is applied only for the determination of calcium (see note under section III, 2 (e)).

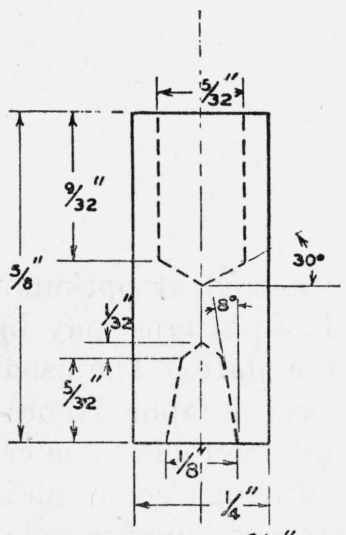

A. ANODE CAP $9 / 32$ " CUP

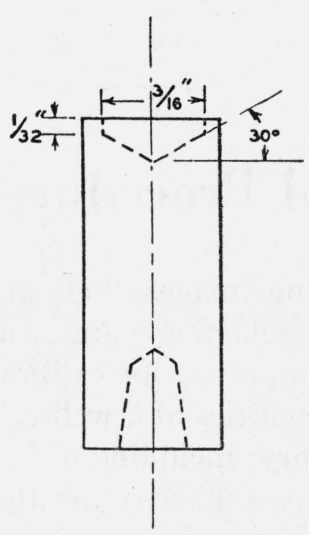

B. ANODE CAP $1 / 32$ " CUP

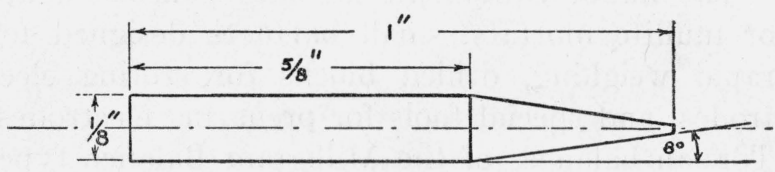

C. CATHODE

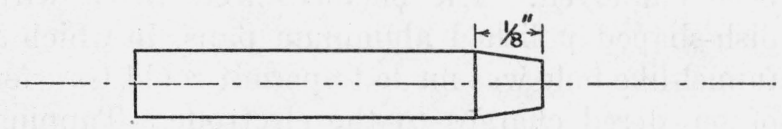

D. ANODE PEDESTAL

Figure 5.-Electrode shapes.
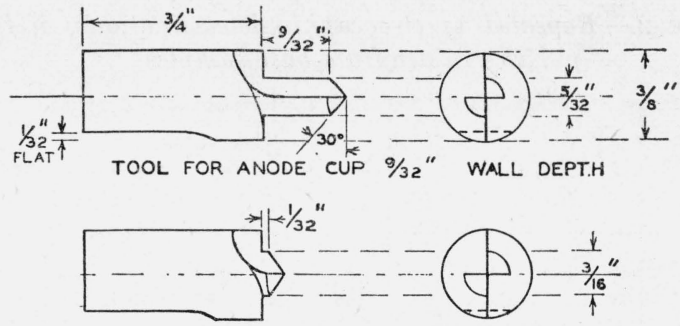

TOOL FOR ANODE CUP $1 / 32$ " WALL DEPTH
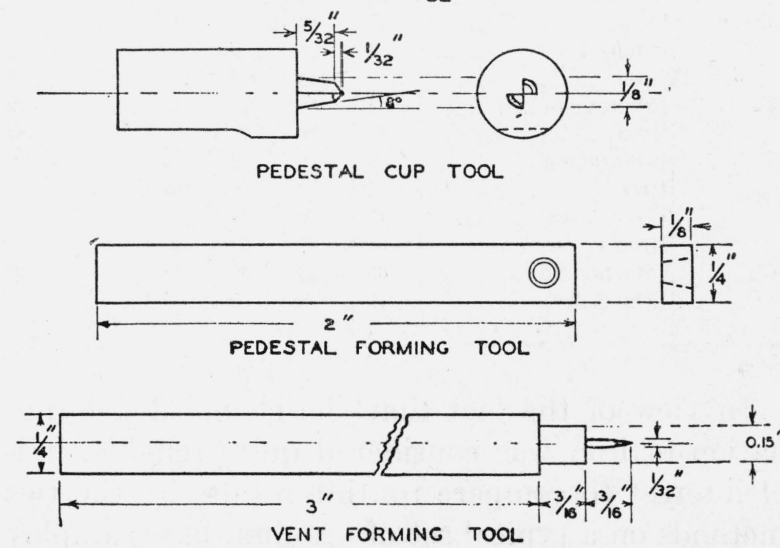

FIGURE 6.-Tools employed in preparing electrodes.

\section{Analysis of Uranium-Base Materials}

\section{(a) Preparation of the Sample}

Samples of uranium-base materials not in the form of the black oxide $\mathrm{U}_{3} \mathrm{O}_{8}$ are converted to this refractory form prior to analysis. Procedures for the conversions were established in the Bureau's chemistry division by C. J. Rodden and others, as follows. Uranium metal in pellet form and various oxides may be ignited in a furnace at $800^{\circ}$ to $900^{\circ}$ $\mathrm{C}$ in quartz dishes for 2 or 3 hours or overnight. Powdered uranium metal is highly pyrophoric and should be ignited cautiously by warming small amounts in a quartz dish in the open. Salts such as the acetate and nitrate may be converted in platinum dishes, beginning at $350^{\circ} \mathrm{C}$, stirring the sample until the compound is decomposed, and then completing the ignition at $800^{\circ} \mathrm{C}$. The conversion of halide salts by this procedure may result in losses of volatile impurities as halides. To minimize losses, the salts may be hydrolyzed and the ignition completed as before. Ignition generally results in loss of mercury and, in the case of halides, of boron as well. In certain cases (oxides, tetrafluoride) the original sample is examined for these elements by a carrier-distillation procedure in which the exposure is limited to 15 
seconds, beginning when the arc is struck. The determination of cadmium in samples in which arsenic exceeds $50 \mathrm{ppm}$ requires the removal of arsenic to avoid the interference of the lines As 2288.12 A and Cd 2288.02 A. The arsenic may be removed from a portion of the sample by treatment with portions of concentrated $\mathrm{HBr}$. The salt is finally converted to oxide.

In preparing the black oxide sample for spectrographic analysis, a 4 - or 5 -g portion is ground for 10 minutes to eliminate segregation. Then a portion of 200 to $1,500 \mathrm{mg}$, depending on the number of runs to be made, is ground with the carrier in the proportion of 98 parts $\mathrm{U}_{3} \mathrm{O}_{8}$ to 2 parts $\mathrm{Ga}_{2} \mathrm{O}_{3}$. A charge of $100 \mathrm{mg}$ of the mixture is transferred to a graphite anode having a $\% 32$-in. cup. Similar electrodes are prepared for the sample in duplicate and for selected check standards. Prior to making the exposures, the charge is provided with a vertical vent hole, employing the vent-forming tool shown in figure 6 . In general, eight exposures, including two or three standards are made on a 4 - by 10 -inch photographic plate; each exposure represents five steps of the step sector, with a total spectral-line length of $10 \mathrm{~mm}$. The large number of elements determined and the sensitivities required, involves the observation of spectra in several regions of spectrum, as described in the following sections.

\section{(b) General Procedure: Determination of 26 Elements}

This procedure provides for the determination of as many elements as possible on a single 4 - by 10 -inch spectrogram in the ultraviolet region of the spectrum. The remaining procedures $c, d, e$, and $f$ are modifications of the general procedure for the purposes of (1) increasing the accuracy or the sensitivity in certain cases, and (2) observing elements not having their most sensitive lines in the general region. The elements determined in the general procedure include iron, magnesium, and manganese, which are determined with highest accuracy in procedure (c), and sodium, which is observed in procedure (e) when the highest sensitivity is required for this element. Boron and silicon are determined by photometric measurement. The conditions and wavelengths employed are given in table 4. The ultimate lines $\mathrm{Mg}$ 2852.13, $\mathrm{Ni} 3414.76$, and Sn 3175.04 do not appear in the list because of the availability of other lines sufficiently sensitive and more conveniently located for observation.

TABLE 4.-Spectral observations for the general procedure Determination by visual inspection: $\mathrm{Ag}, \mathrm{Al}, \mathrm{As}, \mathrm{Au}, \mathrm{Be}, \mathrm{Bi}, \mathrm{Co}, \mathrm{Cr}, \mathrm{Cu}, \mathrm{Fe}$, $\mathrm{Ge}, \mathrm{In}, \mathrm{Mg}, \mathrm{Mn}, \mathrm{Mo}$, (Na), Ni, P, $\mathrm{Pb}, \mathrm{Sb}, \mathrm{Sn}, \mathrm{Tl}, \mathrm{V}, \mathrm{Zn}$.

Determination by photometric measurement: B, Si. Region: 2200 to $3500 \mathrm{~A}$, First order $5.6 \mathrm{~A}$ per $\mathrm{mm}$.

Plate: Eastman Spectrum Analysis No. 1.

Pre-arc period: 5 seconds.

Exposure period: 35 seconds.

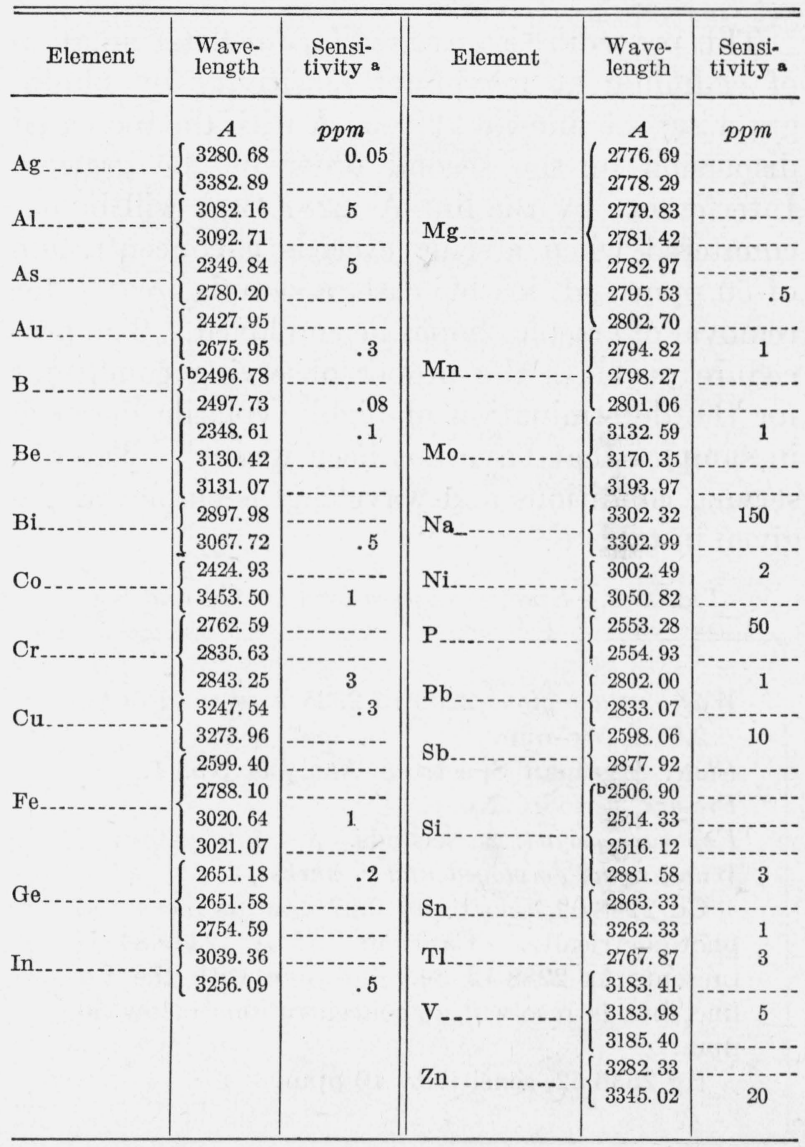

a The limit of detection is indicated for the line of greatest sensitivity.

b These lines are employed for photometric measurement in this procedure.

\section{(c) Improved Determination of Fe, $\mathrm{Mg}$, and $\mathrm{Mn}$}

This procedure is identical with that of procedure (b), except that the carrier contains chromium, added as an internal standard for the determination of iron, magnesium, and manganese by photometric measurement. The carrier is composed of $\mathrm{Ga}_{2} \mathrm{O}_{3}$ containing 1 percent of chromium as $\mathrm{Cr}_{2} \mathrm{O}_{3}$. The wavelengths employed are given in table 5 . 
TABLE 5.-Analytical line pairs for the determination of $\mathrm{Fe}, \mathrm{Mg}$, and $\mathrm{Mn}$

\begin{tabular}{|c|c|}
\hline \hline Wavelengths, A & $\begin{array}{c}\text { Index } \\
\text { value a }\end{array}$ \\
\hline & $p p m$ \\
Fe II, $2599.40 / \mathrm{Cr}$ II, 2762.59 & 63 \\
$\mathrm{Mg}$ II, $2802.70 / \mathrm{Cr}$ II, $2843.25 \ldots$ & 12 \\
$\mathrm{Mn}$ I, $2798.27 /$ Cr. II, 2843.25 & 40 \\
\hline
\end{tabular}

a The index value in the table is the concentration of the element for which the intensity ratio of the pair of lines is unity.

\section{(d) Determination of $\mathrm{Cd}$ and $\mathrm{Hg}$}

This procedure is designed for the determination of cadmium at maximum sensitivity by photographing the line Cd 2288.02 A with the increased dispersion of the second order of the grating. Interference by the line As $2288.12 \mathrm{~A}$ will be encountered when arsenic exceeds a concentration of $50 \mathrm{ppm}$ and, in this case, a sample treated for removal of arsenic should be employed. The procedure provides the proper observing conditions for the determination of highly volatile mercury in samples that have not been ignited. The observing conditions and wavelengths employed are given in table 6 .

TABLE 6.-Spectral observations for $\mathrm{Cd}$ and $\mathrm{Hg}$

Wavelength region: 2200 to $2935 \mathrm{~A}$, second order $2.8 \mathrm{~A}$ per $\mathrm{mm}$.

Plate: Eastman Spectrum Analysis No. 1.

Pre-arc period: None.

Exposure period: 25 seconds.

Wavelengths employed and remarks:

Cd 2288.02, sensitivity $0.07 \mathrm{ppm}$, is measured photometrically. Caution: If $\mathrm{As} 2349.84$ is present, As 2288.12 may interfere with the Cd line, but is resolved at concentrations below 50 ppm.

$\mathrm{Hg}$ 2536.52, sensitivity $10 \mathrm{ppm}$.

\section{(e) Determination of $\mathrm{Ba}, \mathrm{Li}$, and $\mathrm{Na}$}

This procedure provides for highest sensitivity in the determination of lithium and sodium by photographing the spectrum in the visible region. The region is convenient also for the determination of barium. ${ }^{4}$ An analytical curve was es-

4 Calcium is determined by a complete-burn procedure employing a shallow cup electrode with a charge of $5 \mathrm{mg}$ of the sample mixture prepared for the carrier-distillation method. A 10 -ampere are is employed, and the spectrum is photographed in the region of the calcium line 3933.67 A with an Eastman Spectrum Analysis No. 1 plate. The sensitivity of detection for calcium is $2 \mathrm{ppm}$. A procedure for the determination of strontium was not established. tablished for the photometric measurement of Li 6707.84 A, but lithium is seldom detected and measurements are not regularly made. The conditions employed are given in table 7 .

TABLE 7.-Spectral observations for $\mathrm{Ba}$, Li and $\mathrm{Na}$

Wavelength region: 5700 to 7000 A, first order $5.5 \mathrm{~A}$ per $\mathrm{mm}$.

Plate: Eastman Spectroscopic II-F.

Pre-arc period: None.

Exposure period: 40 seconds.

\begin{tabular}{|c|c|}
\hline Wavelength & Sensitivity \\
\cline { 1 - 2 } $\mathrm{Ba}, 6141.72 \ldots$ & 10 \\
$\mathrm{Li}, 6707.84 \ldots 9$ & 0.1 \\
$\mathrm{Na}\left\{\begin{array}{l}5889.95 \\
5895.92 \ldots\end{array}\right.$ \\
\end{tabular}

\section{(f) Determination of $\mathrm{Cs}$, $\mathrm{K}$, and $\mathrm{Rb}$}

This procedure is identical with that of procedure (e) except that the spectrum is photographed in the infrared region for high sensitivity of detection of cesium, potassium, and rubidium. The conditions employed are given in table 8.

TABLE 8.-Spectral observations for $\mathrm{Cs}, \mathrm{K}$, and $\mathrm{Rb}$

Wavelength region: 7450 to $8750 \mathrm{~A}$, first order 5.5 A per $\mathrm{mm}$.

Plate: Eastman Spectroscopic I-N.

Pre-arc period: None.

Exposure period: 40 seconds.

\begin{tabular}{|c|c|}
\hline Wavelengths & Sensitivity \\
\hline Cs, 8521.10 & $p p m$ \\
$\mathrm{~K}\left\{\begin{array}{l}7664.91 \\
7698.98\end{array}\right.$ & 8 \\
$\mathrm{Rb}, 7800.23$ & $\frac{2}{1}$ \\
\hline
\end{tabular}




\section{Summary}

A method of fractional distillation for spectrographic analysis is described for the separation of volatile impurities from a refractory sample matrix. The separation is obtained by the addition of a small amount of a selected volatile carrier material to the refractory sample, followed by partial distillation of the mixture in a d-c arc electrode assembly of improved design. The actions of the carrier (1) to sweep out the minute quantities of impurity vapors, and (2) to stabilize the arc, result in high sensitivity and accuracy for the determination of 33 impurity elements at concentrations of a few parts per million or less in uranium-base materials. The accuracy observed for determinations of $\mathrm{B}, \mathrm{Cd}, \mathrm{Fe}, \mathrm{Mg}, \mathrm{Mn}$, and $\mathrm{Si}$, by photometric measurement, was \pm 10 percent. The method was applied to control and inspection in the production of high-purity uranium metal, oxides, and salts within the Manhattan Project.

The authors gratefully acknowledge the assistance of the following in the development of this work: Dorothy Grosch, Ruth G. McGregor, Mary Jo Adrian, Virginia C. Stewart, and J. Dudley Richards.

\section{References}

[1] H. D. Smyth, A general account of the development of methods of using atomic energy for miltiary purposes under the auspices of the United States Government, 1940-1945, U. S. Government Printing Office, Washington (1945).

[2] C. C. Kiess, C. J. Humphreys, D. D. Laun, J. Research NBS 37, 57 (1946) RP 1729.

[3] W. R. Mott, Trans. Am. Electrochem. Soc. 34, 255 (1918).

[4] W. R. Mott, Trans. Am. Electrochem. Soc. 37, 665 (1920).

Washington, May 13, 1946.
[5] S. P. de Rubies and J. Doetsch, Z. anorg. Chem. 220, 119 (1934).

[6] S. P. de Rubies and J. M. L. de Azcona, Anales soc. españ. fís. quím. 34, 307 (1936).

[7] E. Preuss, Z. angew. Mineral. 3, 8 (1940).

[8] G. R. Harrison and R. Kent III, Spectrographic determination of trace materials in uranium salts and in magnesium, lime and dolomite (publication pending Manhattan Project Technical Series).

[9] J. I. Hoffman, J. Research NBS 13, 665 (1934) RP 734.

[10] B. F. Scribner and C. H. Corliss, J. Research NBS 30, 41 (1943) RP 1515. 